\title{
IN SITU STRESS MEASUREMENT NEAR FAULTS AND INTERPRETATION BY MEANS OF DISCRETE ELEMENT MODELLING
}

\author{
Leandro R. ALEJANO ${ }^{1) *}$, Uxía CASTRO-FILGUEIRA ${ }^{1)}$, Anna Maria FERRERO ${ }^{2)}$, \\ Maria MIGLIAZZA $^{3)}$ and Federico VAGNON ${ }^{2)}$
}

\author{
${ }^{1)}$ Department of Natural Resources \& Environmental Engineering, University of Vigo, Campus Lagoas Marcosnde s/n, 36.320 Vigo, Spain \\ 2) Department of Earth Science, Università degli Studi di Torino, via Valperga Caluso 35, 10125 Torino, Italy \\ 3) Department of Earth Sciences "A. Desio", University of Milano, via Luigi Mangiagalli, 34, 20133 Milan, Italy
}

*Corresponding author's e-mail: alejano@uvigo.es

\begin{tabular}{l}
\hline ARTICLE INFO \\
\hline Article history: \\
Received 3 November 2016 \\
Accepted 17 January 2017 \\
Available online 2 February 2017 \\
\hline
\end{tabular}

Keywords:

Underground Quarries

Marble

Rock Stress

Stress Measurements

Faulted Rock Mass

\begin{abstract}
The design of underground caverns of significant size and of complex geometry is often accompanied by the use of numerical models able to estimate the range of stresses and strains induced by the excavations and, consequently to evaluate the stability of the caverns. In this context, it is convenient to estimate the natural state of stress of the rock mass, the mechanical properties of the rock matrix and the discontinuities and to carry out in situ measurements to calibrate the model. In the Carrara basin (Italy) there is a huge number of underground excavations that need to be monitored and, for this purpose, a series of models and in situ measurements have been performed. This study aims to point out the difficulties involved in understanding the in-site measured stress. A series of tests were conducted in Carrara, in an underground marble quarry site, focusing to study the complex tectonic environment in the area. A series of comparisons between 3D DEM numerical models has been performed in order to understand the influence of the presence of the main faults on the in situ state of stress. Some final comments regarding the variability of stress fields in faulted rock masses are provided.
\end{abstract}

\section{INTRODUCTION}

Quarry excavation design has been traditionally developed based solely on previous experience and, more recently it tends to be based on rock mass classification systems. However, a more rigorous approach conveys defining or having an idea about the natural rock stress field affecting the area of interest, the mechanical properties of the rock matrix and the orientation, geometry and geomechanical parameters of discontinuities occurring in the rock mass where the void is located. The Carrara basin in Italy contains a large number of existing underground excavations constructed based on traditional design approaches, so monitoring is extremely convenient to check the safety of the existing mining voids.

Understanding the in situ stress on the Earth's crust is an important component of many rock engineering problems. The stress in rocks can be indirectly measured only at certain points, and the in situ determination of the stress state at a larger scale involves many assumptions and is influenced by various factors, one of the most important of which is the presence of discontinuities. Discontinuities, and particularly faults, have a relevant influence on the magnitude and orientation of the stress components in rock. The results of in situ measurements indicate that re-orientation and changes in magnitude of principal stresses occur close to the discontinuities and that jumps in the stress (or stress discontinuity) take place in one side of the discontinuity (Amadei and Stephansson, 1997).

The role of discontinuities in such scenarios is a topic of interest since it can indeed produce some instability phenomena; as Diederichs (1999) or Waclawik et al. (2013) have noted, the stresses in a rock mass play a relevant role. Instability phenomena associated to faults in shallow underground environments have been recorded and presented in the literature (Alejano et al., 1999, 2008). The estimation of the stress state in rock masses containing these shallow underground ornamental rock quarries is therefore a topic of interest to researchers.

Understanding and estimating the stress state of rock has become increasingly relevant over the last quarter of the twentieth century, when numerical models became one of the most popular rock engineering design tools in use (Konietzky and te Kamp, 2004; Segalini et al., 2009). It has not always been easy to obtain precise values for the components of an in situ rock stress state (Hudson and Cornet, 2003; Savchenko and Gorbatsevich, 2012). Moreover, several studies have shown that the stress field can contain major local variations and scattered patterns in jointed rock masses (Hudson, 2010; Burtan et al., 2014). Although stress estimation methods in general can be considered reliable, it is still extremely difficult to interpret individual and combined measurements and the local and general in situ stress states, as well 

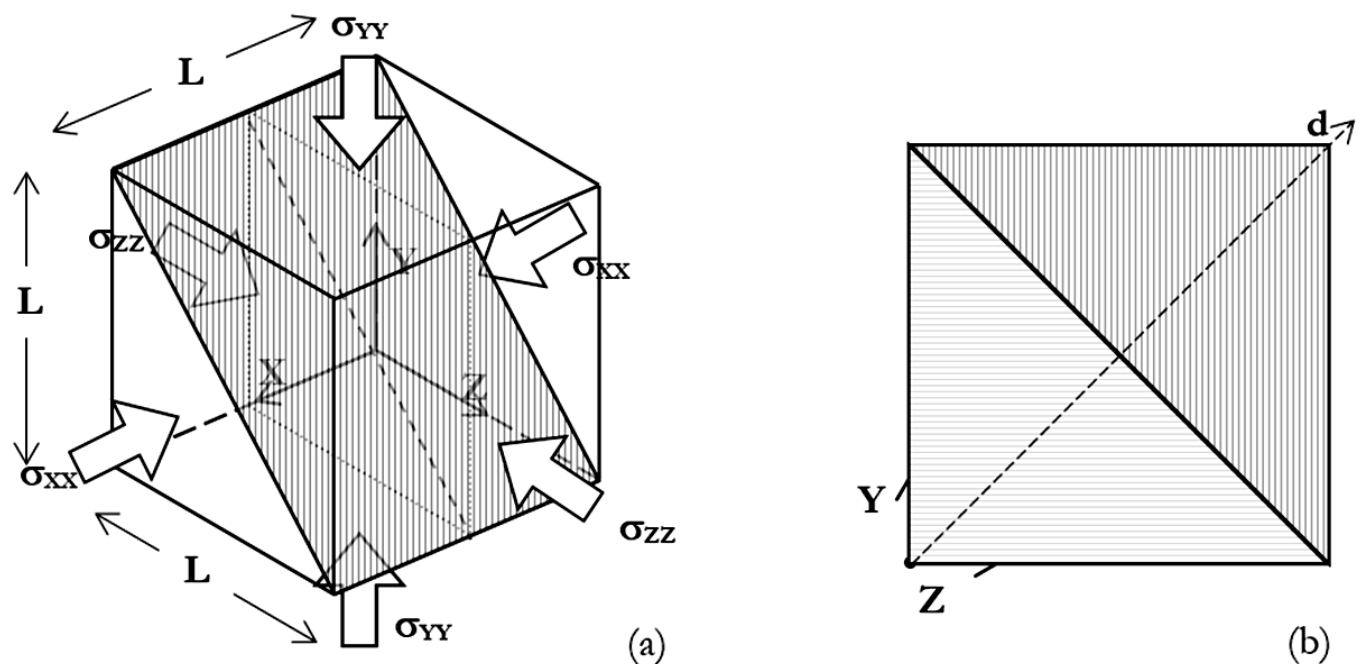

(a)

(b)

Fig. 1 Geometry of the 3D DEM model and its loading condition (a) and the vertical section used to compare results (b).

as compare these measurements with predictions from numerical modelling (Hudson and Cornet, 2003). Overcoming these obstacles was one of the main goals of the present study.

Numerical models appear to be useful when planning stress estimation projects interpreting measurements. In fact they can help to connect geological parameter variations in the establishment of a stress model for the site (Stephansson and Zang, 2012). Some examples of cases where a stress field model can be established in a reasonably accurate manner can be found in literature (Ferrero et al., 2013; Figueiredo et al., 2014), in cases where faults do not play a relevant role. These models should include as much of the significant geological structure affecting the rock mass stress distribution as possible. Faults are particularly relevant because they can produce significant variations in the stress distribution inside a rock mass (Matsuki et al., 2009).

These conditions make it necessary to strike a balance between oversimplification and complexity in a numerical model, a task that requires considerable judgment. An appropriate model can help in the design of field measurements by suggesting optimal locations for the tests, and it can assist in the interpretation of stress measurements. Although a stress estimation project can usually provide valuable information of great value for a particular design project, it is important to be aware of how this information is used. The main goal of stress estimation should be to gain an understanding of the stress state and its variability over a region. One or two measurements at specific locations may not be enough to allow for extrapolation to a larger region. In mountainous areas, the topographic effect can result in considerable local variability in the stresses (Fairhurst, 2003).

\section{SIMPLE MODELS OF STRESS IN PRESENCE OF A SINGLE DISCONTINUITY}

To determine the effect of the presence of a single discontinuity and its strength characteristics on the variation of an induced stress field, in terms of both magnitude and orientation of the principal stresses, Su and Stephansson (1999), have conducted numerical modelling using the distinct element method in a bi-dimensional field (UDEC, Itasca, 2005). The process involves a model made up of two blocks separated by a discontinuity and subject to a bilateral stress state acting on the boundary. The blocks display linear elastic behaviour, and the discontinuity has a stress associated with it associated to the Mohr-Coulomb shear strength criterion.

As expected, the orientation of the principal stresses close to the discontinuity tends to be parallel and perpendicular to the discontinuity itself, but it may progressively turn as it moves away from the discontinuity to matches the direction of the principal stresses at the boundary. Parametric analyses have made it possible to conclude that the re-orientation range of the stresses is determined mainly by the friction angle $(\phi)$ of the discontinuity, and, to a lesser extent, by the lateral confinement coefficient $\left(k_{o}\right)$ and the angle between the discontinuity and the direction of the maximum principal stress applied at the boundary $(\sigma)$. The orientation range diminishes as the friction angle increases.

Analogous distinct element numerical modelling has been conducted to review and complete the study initiated by Su and Stephansson (1999) in a 3D field (3DEC, Itasca, 2005) by assuming the tri-dimensional computational model is a cube (Fig. 1) made up of two blocks separated by a discontinuity and subjected to a normal stress field applied at the boundary. Like the previous model, the blocks have been assumed to have linear elastic behaviour and the discontinuity's strength has been expressed through the Mohr- 


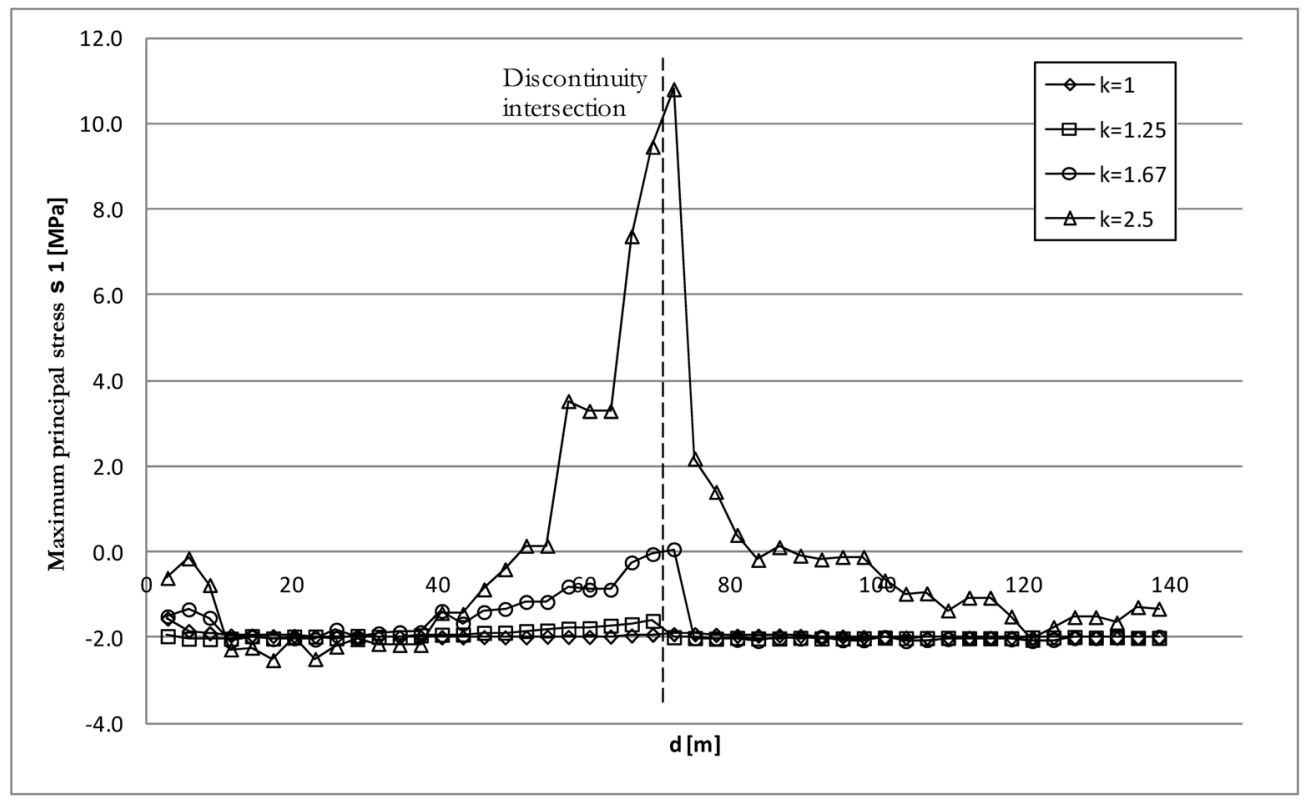

Fig. 3 Maximum principal compression stresses.

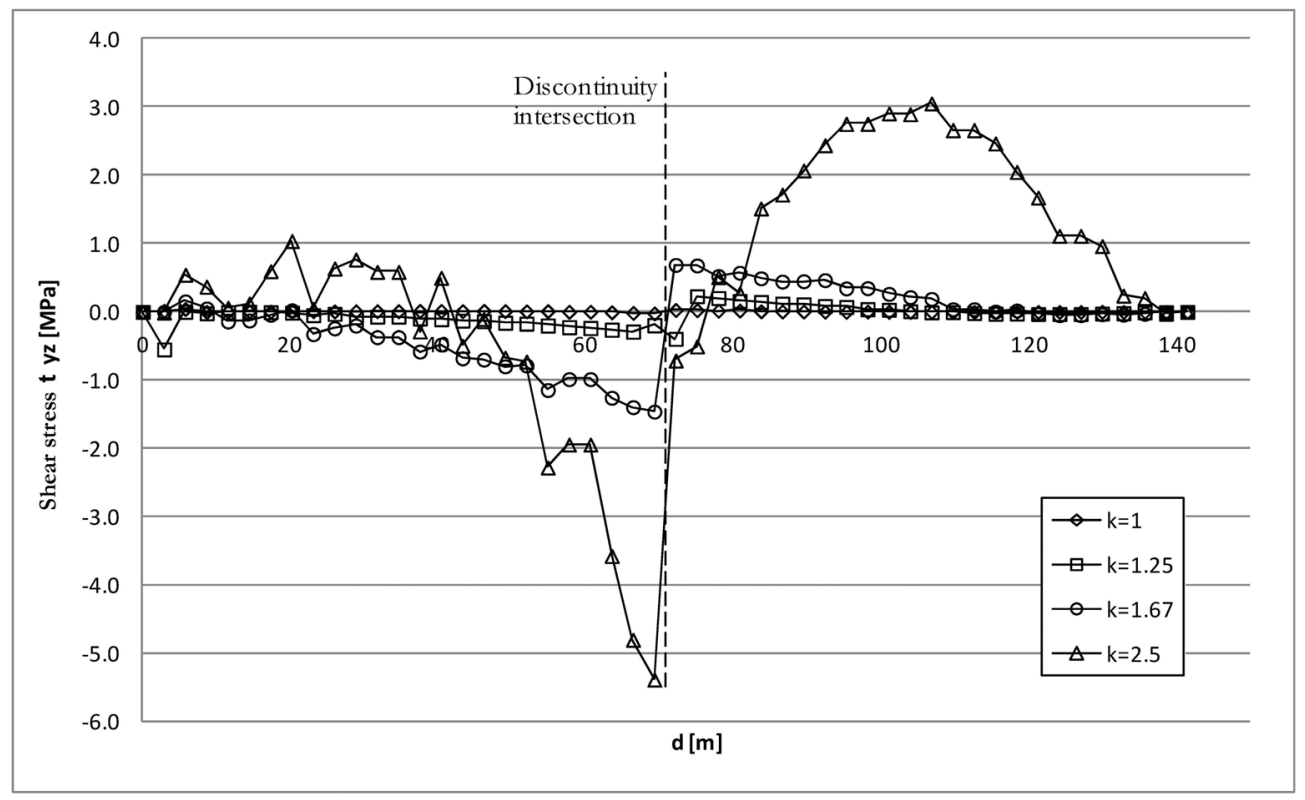

Fig. 4 Shear stresses along the discontinuity.

Coulomb criterion, while the cohesive contribution has been considered non-existent. A series of parametric analyses have been conducted by varying the stress state applied at the boundary and the friction angle of the discontinuity. In particular, the lateral stress coefficient $k_{o}$ (considered constant in the $x$ and $y$ directions) has been varied between 1 and 2.5 , while the friction angle has been varied between 0 and $35^{\circ}$.

It can be observed that the orientation of the principal stresses close to the marginal zones are equivalent to those of the stresses applied at the boundary along a vertical section passing through the centre of the model (Fig. 2). However, it is also observed that the principal stresses turn progressively in relation to the central zone, which is influenced by the presence of the discontinuity, until they are oriented parallel and perpendicular to the discontinuity itself.

The influence of the stress state applied at the boundary has been evaluated considering the lateral thrust coefficient values of $1,1.25,1.67$ and 2.5 , and attributing a friction angle of $3^{\circ}$ to the discontinuity. The results have been compared by analysing the trend of the maximum principal stresses (Fig. 3) and the tangential stresses (Fig. 4) along an alignment perpendicular to the discontinuity and passing through the central point of the model (alignment $d$ in Fig. 1). It should be noted that the difference in the principal stresses $\Delta \sigma$ in the zone surrounding the discontinuity increase with an increase in the lateral stress coefficient $k_{o}$, as do the tangential stresses. 


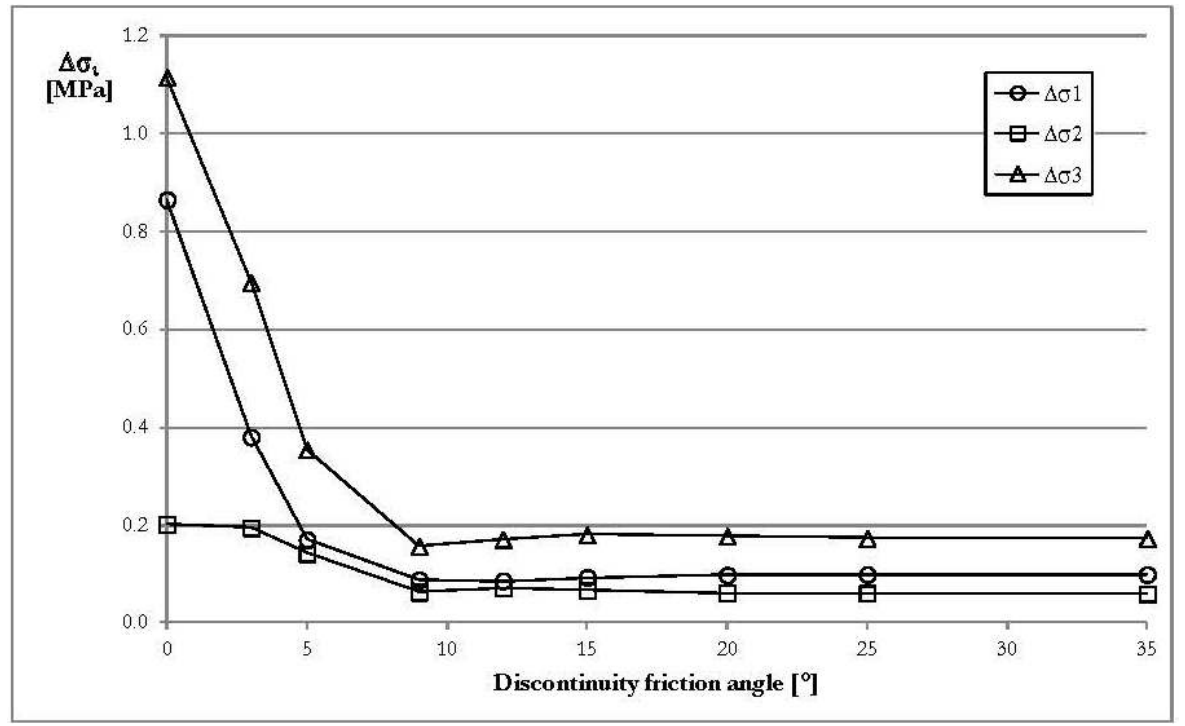

Fig. 5 Differences in the principal stresses corresponding to the discontinuity in the friction angle function $\left(k_{o}=1.25\right)$.
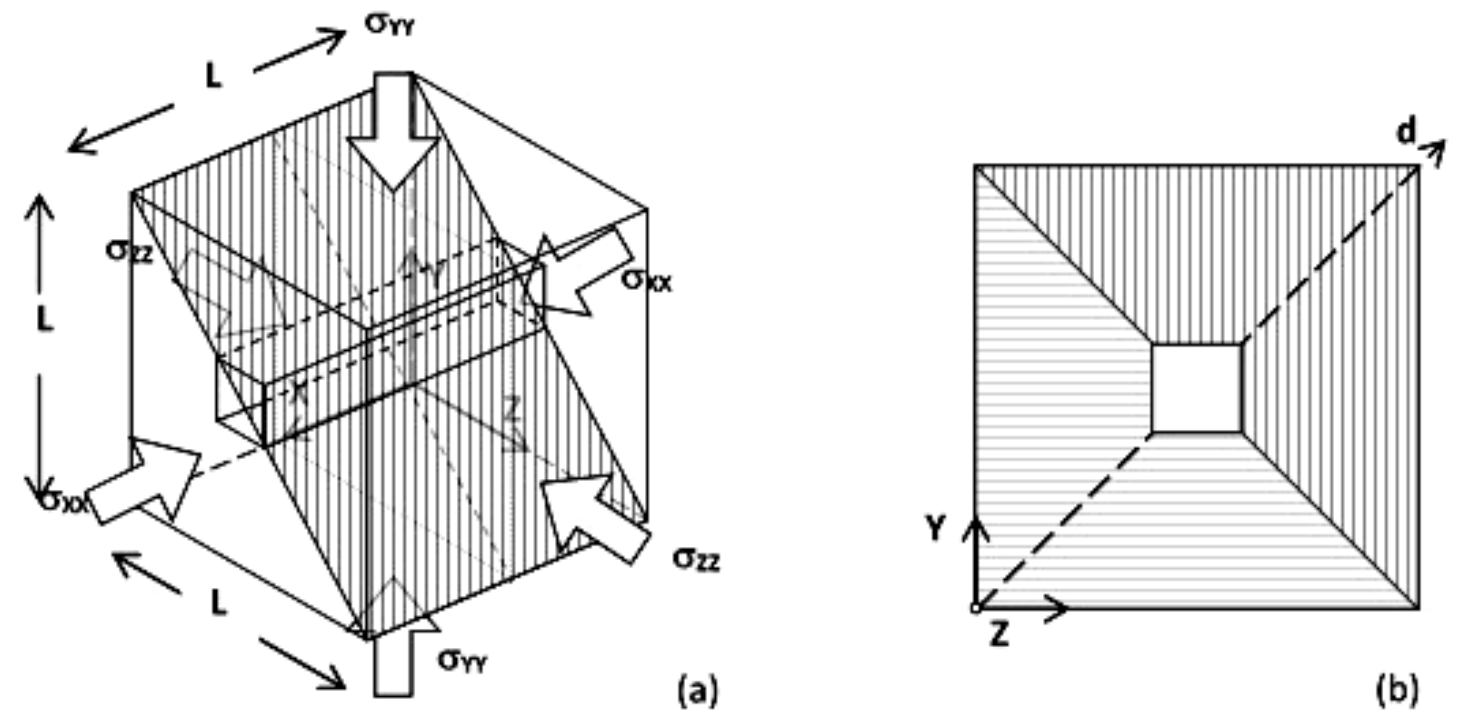

(a)

(b)

Fig. 6 Configuration of the model and reference system.

The influence of the discontinuity's strength characteristics has been analysed considering a stress state at the boundary with a $k_{o}$ value of 1.25 and a variable discontinuity friction angle. The effect of this parameter can be observed in Figure 5, which shows the difference in the maximum principal stress values calculated along the alignment at two points on either side of the discontinuity. It can be seen that the maximum difference in the maximum principal stresses occurs at an angle of $0^{\circ}$ in the conditions shown in the figure, while the difference is eliminated at constant friction angle values above $15^{\circ}$.

The same model has been used to analyse the effects of a discontinuity on the border of an underground void (Fig. 6). The same parametric analyses have been conducted (variation in the stress state at the border and variations in the friction angle), and the results indicate the re-orientation of the stresses near the discontinuity (Fig. 7). As predicted, the excavation has caused an increase in the stresses compared to the example without underground voids. A major concentration of stresses can be observed at the tunnel edges in particular.

Extra joints were introduced into the model to help create the underground void. The mechanical properties of the artificial joints are set in a way that the joints do not influence the model continuity and they do not affect the stress distribution.

The variations in the components of the principal stresses have been compared to the case without discontinuities to consider the effect of the discontinuity's mechanical characteristics along alignment $d$. The maximum variation in each principal stress component is shown in Figure 8 for variations in the strength angle attributed to the discontinuity. In all analysed cases the maximum variation of all the principal components of stress has been computed in a point close to the excavation edge. 

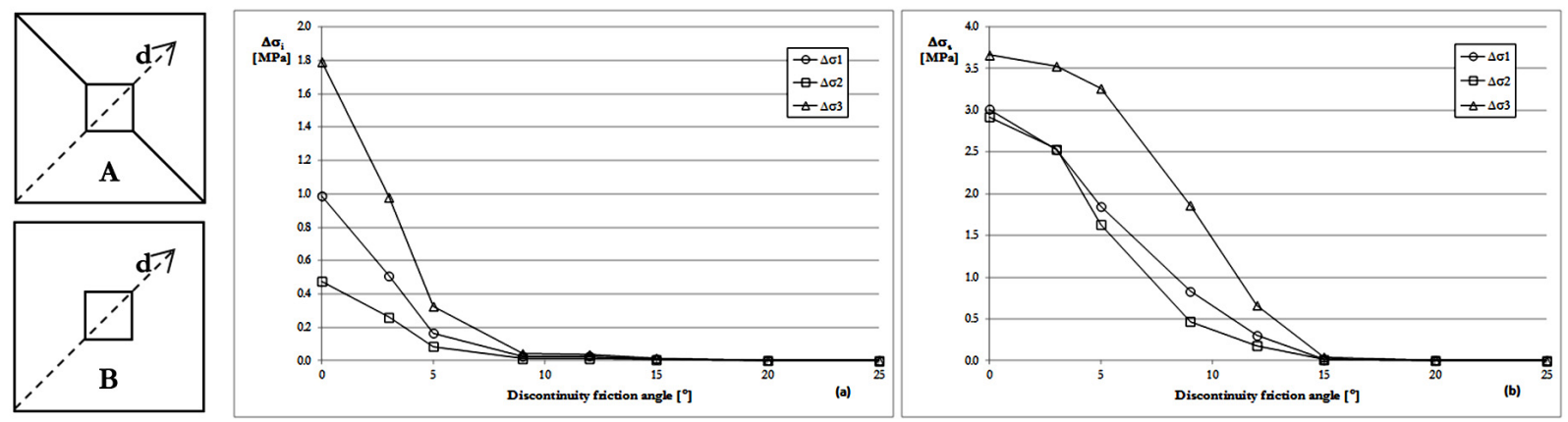

$$
\Delta \sigma_{i}=\max \left[\Delta \sigma_{i A}(d)-\Delta \sigma_{i B}(d)\right]
$$

Fig. 8 Differences in the maximum principal stresses corresponding to the discontinuity in the friction angle function: a) $k_{o}=1.25$; b) $k_{o}=1.67$.

The model reported in Figure 7 has the same dimensions of the $2 \mathrm{D}$ model published by $\mathrm{Su}$ and Stephansson (1999), since the main objective of this part of the paper is to compare the influence of the 2D model instead of a 3D model. The overall behaviour of the model is not affected by the boundary conditions, since Figures 3 and 4 clearly show how both maximum principal stresses and shear stress are decreasing to a constant value when they are far enough from the discontinuity intersection, for all the $k_{0}$ values analysed.

These numerical modelling analyses have made it possible to conclude that the friction angle $\phi$ has a major influence on the re-orientation range of the stresses is and, in particular, that this range decreases with an increase in the friction angle and a decrease in $k_{o}$. These results have shown that the interpretation of stress states measured close to important discontinuities should be accounted for using discontinuity approaches that are capable of simulating the rotation of stresses corresponding to weakness planes.

\section{STRESS MEASUREMENTS AT A CARRARA QUARRY}

In this section, we present an interpretation of stress measurements performed in the vicinity of an underground excavation in the Carrara marble basin of Italy using 3D numerical modelling. The study used the over-coring measurement method, which is based on the principle of over-coring a pilot hole in which the soft inclusion measuring cell is to be installed. The principle of the soft cell is based on the theory of linear elasticity for continuous, homogenous and isotropic rocks (Sjöberg et al., 2003). The complete stress tensor at the test location was determined by measuring six strain components in different directions on the wall of a borehole. The CSIRO hollow inclusion (HI) triaxial strain cell was used. This cell allows, in principle, for the complete determination of a stress tensor from a single overcoring operation in one borehole (Worotnicki, 1993; Ljunggren et al., 2003). The stress measurements were conducted in the quarry called "Faniello" in Carrara (Italy) by the technical staff of the Working Environment Safety Office (USL).

The quarry under study was characterised by the presence of three main faults influencing the stress state. For this reason, the study was focused mainly on determining the influence of discontinuities on the stress state with 3D DEM modelling, which can account for the geometric features of rock masses and rock excavation.

\subsection{SITE DESCRIPTION}

The area being mined belongs to the metamorphic Apuan Alps complex and is the result of tectonic and metamorphic phases that occurred during the Alpine orogeny. The current structure of the Apuan Alps is most likely the result of a sharp rise, initiated by an isostatic response to the previous doubling of the continental crust and furthered by the consequent erosion of the Tuscan and Ligurian coatings, which created the tectonic window that allowed the Apuan Alps to emerge. The Alps are a metamorphic complex that originated after a lowgrade metamorphism process (green schist facies) under a pressure of approximately 3-4 kbar and a temperature between $300^{\circ}$ and $400^{\circ}$ Celsius. Limestone takes on significant plasticity under these conditions, and calcite crystals become larger due to the increase in temperature and flatter to offer greater resistance to pressure. The subsequent placement of the rocks is a result of the tectonic lifting of the Earth's crust.

The Apuan quarry under study is located at the end of a valley in the Municipality of Stazzema (MS) at an altitude of $1190 \mathrm{~m}$, and has a very steep topographic surface that, above the excavations, varies between $1200 \mathrm{~m}$ and 1430 m.a.s.l.

A map of the excavations is shown in Figure 9, which indicates the stress state measurement sites and the main faults. These faults were almost parallel and had sub-vertical dips of $86-88^{\circ}$ and dip directions of $150-160^{\circ}$. The mechanical features of the rock material and rock joints (Table 1) were obtained from 
Table 1 Mechanical parameters of intact rock and rock joints: $E=$ Young's modulus; $v=$ Poisson's ratio; $\mathrm{c}_{\mathrm{ir}}=$ intact rock cohesion; $\phi_{i r}=$ intact rock friction angle; $\mathrm{JKN}=$ normal joint stiffness; JKS = shear joint stiffness; $\mathrm{JRC}=$ joint roughness coefficient; $\phi_{j}=$ joint friction angle; $c_{j}=$ joint cohesion.

\begin{tabular}{|c|c|}
\hline & Intact rock features \\
\hline E (GPa) & 40.3 \\
\hline$v(-)$ & 0.182 \\
\hline$c_{\text {ir }}(\mathrm{MPa})$ & 21.4 \\
\hline \multirow[t]{2}{*}{$\phi_{\text {ir }}\left({ }^{\circ}\right)$} & 42 \\
\hline & Rock joint features \\
\hline JKN (GPa/m) & 40.3 \\
\hline JKS (GPa/m) & 17.0 \\
\hline JRC (-) & 12.6 \\
\hline$\phi_{\mathrm{i}}\left({ }^{\circ}\right)$ & 32.3 \\
\hline
\end{tabular}

laboratory tests (including uniaxial compressive, shear and Brazilian tests) on the intact rock and shear tests on the discontinuities of samples gathered from the Carrara basin (Ferrero et al., 2007; Ferrero et al., 2009; Migliazza et al., 2011; Spagnoli et al., 2011).

\subsection{OVER-CORING TESTS}

The portion of the rock mass under investigation was located on the east side of the quarry and had a height of $5 \mathrm{~m}$ at the excavation face. The on-site procedure began by taking stress measurements with over-coring tests using CSIRO cells, which allow for 3D measurements of the actual stress state at the investigated position to be made. The measurements were concentrated in the rock mass portion that characterised the central room of the quarry and were conducted at a height of $1.8 \mathrm{~m}$ from the quarry floor.

Table 2 presents the the positions of the measurements in the boreholes together with the values and the orientations of the principal stress components obtained by applying an elastic solution proposed by Sjöberg et al. (2003). Stereographic projection of the principal measured stress directions is shown in Figure 10.

Table 2 Principal stress components for boreholes 1 and 2.

\begin{tabular}{ccccccccccccc}
\hline $\begin{array}{c}\text { Bore- } \\
\text { hole }\end{array}$ & Test & $\begin{array}{c}\text { Distance } \\
\text { from wall } \\
{[\mathrm{m}]}\end{array}$ & $\begin{array}{c}\text { Boreho- } \\
\text { le dip } \\
{\left[{ }^{\circ}\right]}\end{array}$ & $\begin{array}{c}\sigma_{1} \\
{[\mathrm{MPa}]}\end{array}$ & $\begin{array}{c}\text { Dip } \\
{\left[{ }^{\circ}\right]}\end{array}$ & $\begin{array}{c}\text { Bear } \\
{\left[{ }^{\circ}\right]}\end{array}$ & $\begin{array}{c}\sigma_{2} \\
{[\mathrm{MPa}]}\end{array}$ & $\begin{array}{c}\text { Dip } \\
{\left[{ }^{\circ}\right]}\end{array}$ & $\begin{array}{c}\text { Bear } \\
{\left[{ }^{\circ}\right]}\end{array}$ & $\begin{array}{c}\sigma_{3} \\
{[\mathrm{MPa}]}\end{array}$ & $\begin{array}{c}\text { Dip } \\
{\left[{ }^{\circ}\right]}\end{array}$ & $\begin{array}{c}\text { Bear } \\
{\left[{ }^{\circ}\right]}\end{array}$ \\
\hline \multirow{6}{*}{ BH1 } & 3D1_01 & 1.24 & -3.0 & 29.97 & 12 & 150 & 15.92 & 25 & 245 & 11.44 & 62 & 37 \\
& 3D1_02 & 2.65 & -3.0 & 28.86 & 45 & 148 & 13.97 & 7 & 246 & 9.91 & 44 & 342 \\
& 3D1_03 & 4.65 & -3.0 & 36.00 & 39 & 140 & 17.20 & 26 & 253 & 13.60 & 40 & 7 \\
& 3D1_04 & 8.60 & -3.0 & 30.00 & 35 & 155 & 12.33 & 3 & 64 & 7.60 & 54 & 330 \\
\hline BH2 & 3D1_05 & 11.10 & -4.1 & 26.80 & 15 & 148 & 7.40 & 17 & 243 & 5.50 & 67 & 328 \\
\hline
\end{tabular}
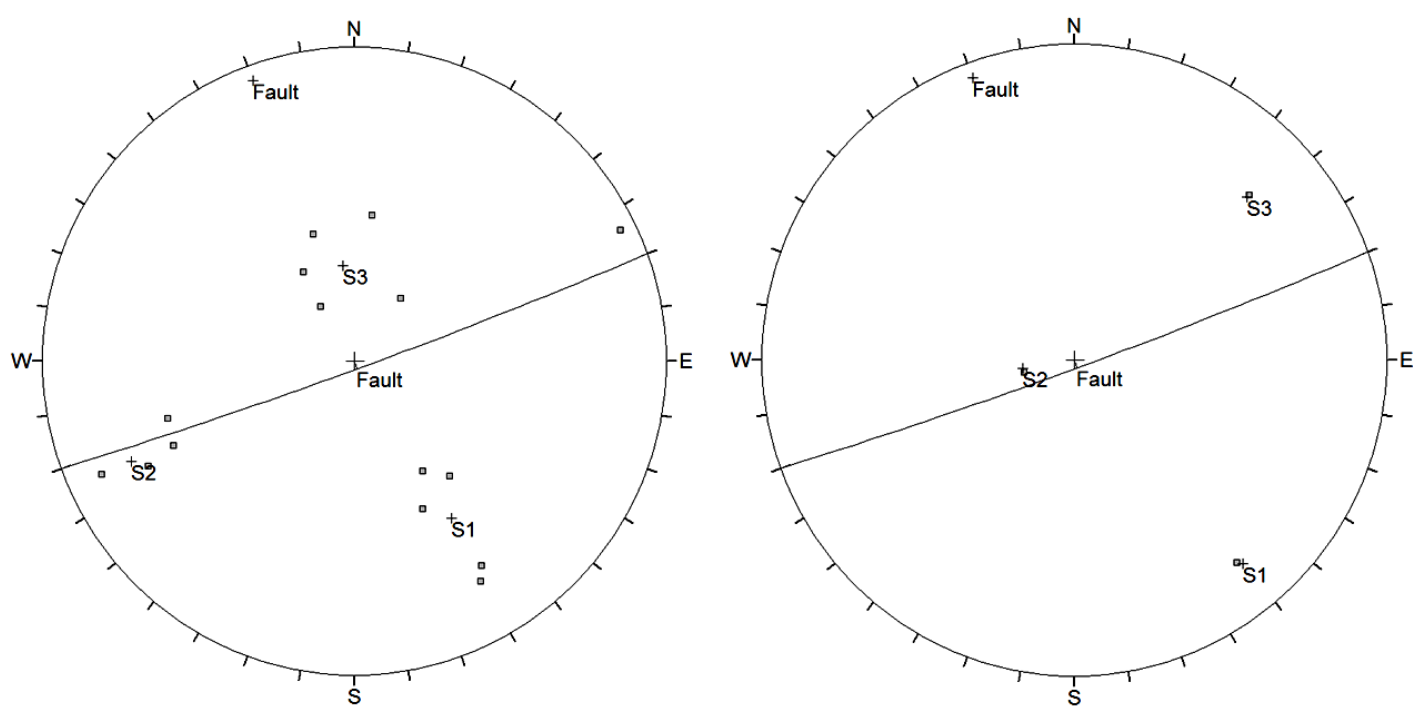

Fig. 10 Representation of the principal stresses' action network from the D1 tests (left) and D2 tests (right). 
Table 3 Mean orientations of the principal stresses obtained during the D1 borehole test.

\begin{tabular}{ccc}
\hline & Trend $\left[{ }^{\circ}\right]$ & Plunge $\left[{ }^{\circ}\right]$ \\
\hline$\sigma_{1}$ & 147 & 29 \\
$\sigma_{2}$ & 244 & 11 \\
$\sigma_{3}$ & 352 & 59 \\
\hline
\end{tabular}

The mean orientations of the principal in situ stresses were obtained with the Dips programme (Rocscience, 2010) and are shown in Table 3.

\subsection{INTERPRETATION}

It should be noted that the principal stresses are not perfectly vertical or horizontal and, above all, that the maximum component $\left(\sigma_{1}\right)$ is not the vertical component. The measured stress state was surely influenced by the presence of the excavations, even at the measurement point farthest from the excavation wall, which was located at a distance $(11.1 \mathrm{~m})$ no greater than twice the characteristic dimension of the excavation (approximately $5 \mathrm{~m}$ ). Considering that these values were the most representative of the quarry's pre-existing stress state, a lateral confinement coefficient $k_{o}$, equal to the ratio between the horizontal stress and the vertical stress in the two horizontal directions $x$ and $z$, was estimated as a first approximation as follows.

A fault with a dip of $87^{\circ}$ and a dip direction of $160^{\circ}$, representing the discontinuities affecting the rock mass under study, was also represented in the stereogram shown in Figure 10. This fault made it possible to see that the line of action of the maximum principal stresses, which we know to be compressive, was perpendicular to the fault in the figure. Thus, we assumed the examined rock mass to be subject to a maximum principal stress perpendicular to the discontinuity planes that tended to close the discontinuities themselves, a mean principal stress $\sigma_{2}$ acted parallel to the discontinuities, and a minimum principal stress $\sigma_{3}$ directed along the vertical direction.

The stress measurement vs. depth are reported in Figure 11, where they are compared with the Kirsch elastic solution, considering an excavation depth that varies between $240 \mathrm{~m}$ (maximum depth) and $125 \mathrm{~m}$ (average depth), an excavation size of $5 \mathrm{~m}$ and a unit weight of $27000 \mathrm{~N} / \mathrm{m}^{3}$.

The measured results were much higher than the values estimated with elastic solutions, even in the maximum overburden scenario (249 m), which confirmed the hypothesis involving the presence of tectonic-type strains.

Moreover, it was necessary to consider the minimum vertical stress to be vertical in this case, while the mean and maximum stresses were subhorizontal and determined by $k_{o}$ values equal to 4 and 1.4, respectively, in the perpendicular horizontal directions ( $x$ and $y$, respectively):

$$
\begin{aligned}
& k_{0 X}=\frac{\sigma_{H}}{\sigma_{V}}=\frac{\sigma_{1}}{\sigma_{3}}=\frac{26,80}{5.50}=4.87 \\
& k_{0 Z}=\frac{\sigma_{H}}{\sigma_{V}}=\frac{\sigma_{2}}{\sigma_{3}}=\frac{7,40}{5.50}=1.35
\end{aligned}
$$

The measurement of the existing stress state, the complexity and articulated geometry of the excavations and the geostructural characteristics of the analysed rock mass, with particular emphasis on the three identified principal faults, showed that it was not possible to analyse this complex situation using $2 \mathrm{D}$

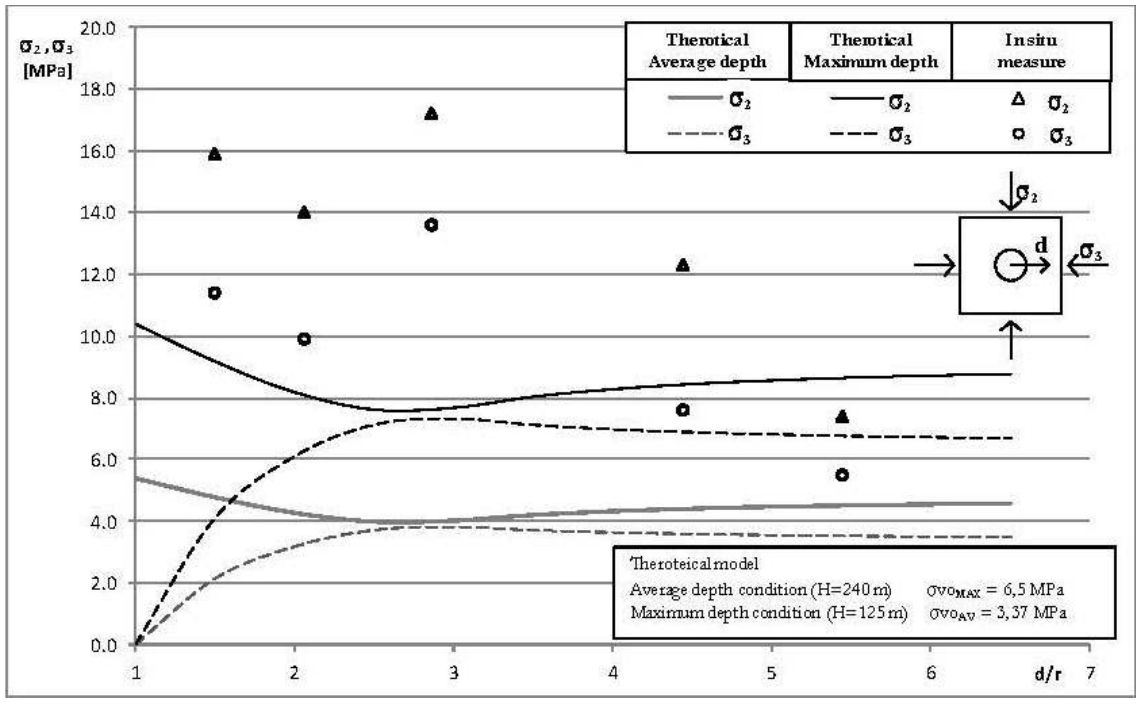

Fig. 11 Comparison between the principal in situ measured stress components and theoretical values calculated in an elastic field for a circular tunnel subject to an anisotropic stress state at different depths. 
models or models that assumed a continuous medium. Instead, it became necessary to employ a 3D discontinuous model.

Sheorey (1994) developed a thermo-elastic-static stress distribution model at the Earth's crust scale, which accounts for Earth's surface curvature, elastic constant variation, average densities of materials and thermal expansion coefficients. Starting from this model he obtained a simple equation to estimate the average lateral thrust coefficient, $k_{o}$, in terms of $z$ (depth in $\mathrm{m}$ ) and $E_{h}$ (elastic modulus of the rock in $\mathrm{GPa})$ as follows:

$$
k=0.25+7 \cdot E_{h} \cdot\left(0,001+\frac{1}{z}\right)
$$

The application of this equation to our case yield large values of $k_{o}$, from more than 6 for a depth of $50 \mathrm{~m}$ to nearly 2 for a depth of 200 meters. If we add to this isotropic approach, the briefly explained highly compressive geological history of this area, it will not be surprising to observe locally large values of horizontal stresses in the area.

\section{ANALYSIS OF THE FANIELLO QUARRY'S STRESS STATE WITH DEM MODELLING}

The numerical modelling performed in this study analysed the portion of the rock mass shown in Figure $12 \mathrm{a}$ and was conducted using the 3DEC (Itasca, 2005) calculation code and considering the mass to be a discontinuous medium. The geometric model (Fig. 12b), which had overall dimensions of $150 \times 75 \times 150 \mathrm{~m}$, represented the area surrounding the portion of the excavation along which the in situ measurements were conducted. The mass had three discontinuity planes that represented the main faults encountered on-site. The model was enhanced by considering the blocks as deformable and having linear elastic isotropic behaviour. The discontinuities were regulated by elastic-plastic type behaviour that considered the collapse scenario according to the Mohr-Coulomb criterion. The values adopted for the physical-mechanical parameters of the rocky matrix and joints are reported in Table 1.

The geometric model was then subjected to a series of parametrical analyses, which were conducted by simulating a variety of initial stress conditions to determine the condition that corresponded most closely to the measured stress state. The examined zone was in fact characterised by a largely abrupt topography (varying from approximately $1430 \mathrm{~m}$ to $1200 \mathrm{~m}$ o.s.l.). A vertical stress state was therefore imposed on the model that considered the remarkable highness variation characterising the Earth's surface in the area of interest (Fig. 12c).

The parametric analyses are summarised in Table 4. Constant and variable overburden or lithostatic stresses were both considered along the extent of the model, including isotropic and anisotropic stress conditions along the horizontal plane with different lateral thrust coefficients and initial stress conditions above the lithostatic stresses.

In all the performed models it was observed, as expected, that the presence of discontinuities (Fig. 13) induced rotation of the principal stresses in all of the study models in the zone where the measurements were conducted. The results obtained from the models were compared in terms of stress, with the maximum principal stress components $\left(\sigma_{1}\right)$ along the points located in the same positions and directions as the in situ test measurements given particular attention.

Comparison between the principal stress component values obtained from the numerical modelling with 3DEC and those obtained from the in situ measurements for a lithostatic hypothesis (Model 1) in all the measurement positions is shown in Figures 14 and 15, while the principal stress orientations are compared in a similar manner in Table 5 .

Even if the orientations of the principal strains do not differ significantly, there is a noticeable discrepancy between the in situ measurements and the modelling results in terms of both the values and the change in the values with depth. The figures show that the numerical modelling underestimated all three of the stress components measured in the rock mass in particular for this example. The complexity of the stress state characterising the rock mass and the articulated geometric conditions of the excavations made the calibration of the model rather complicated, and a back analysis procedure was conducted with the parametric analyses summarised in Table 4. To establish which of the models most closely

Table 4 Parametric analyses.

\begin{tabular}{lcccccccc}
\hline Model & M1 & M2 & M3 & M4 & M5 & M6 & M7 & M8 \\
\hline Lithostatic stress & Yes & Yes & No & No & No & No & No & No \\
$\mathrm{z} \gamma$ & $75 \gamma$ & $75 \gamma$ & $160 \gamma$ & $160 \gamma$ & $160 \gamma$ & $350 \gamma$ & $350 \gamma$ & $400 \gamma$ \\
Horizontal stress & Isotropic & Anisotro- & Anisotro- & Anisotro- & Anisotro- & Isotro- & Anisotro- & Anisotro- \\
& & pic & pic & pic & pic & pic & pic & pic \\
$\mathrm{k}_{\mathrm{ox}}$ & 1 & 4 & 4 & 4 & 4 & 1 & 2 & 2 \\
$\mathrm{k}_{\mathrm{oy}}$ & 1 & 1 & 1 & 1 & 1.4 & 1 & 1 & 1.5 \\
Slope geometry & $\mathrm{Yes}$ & Yes & Yes & No & Yes & Yes & Yes & Yes \\
$\sigma_{\mathrm{xx}}$ & 5.28 & 21.14 & 30.35 & 30.35 & 30.35 & 12.74 & 25.47 & 28.18 \\
$\sigma_{\mathrm{yy}}$ & 5.28 & 5.28 & 7.59 & 7.59 & 7.59 & 12.74 & 12.74 & 14.09 \\
$\sigma_{\mathrm{zz}}$ & 5.28 & 5.28 & 7.59 & 7.59 & 10.62 & 12.74 & 12.74 & 21.14 \\
\hline
\end{tabular}


Table 5 Comparison of the mean data obtained from the D1 numerical modelling and those obtained from the in situ measurements.

\begin{tabular}{|c|c|c|c|c|c|c|c|c|}
\hline \multirow{3}{*}{$\begin{array}{l}\text { Principal } \\
\text { stress }\end{array}$} & \multicolumn{4}{|c|}{ BH1 } & \multicolumn{4}{|c|}{$\mathrm{BH} 2$} \\
\hline & \multicolumn{2}{|c|}{ On site measurement } & \multicolumn{2}{|c|}{ 3D model } & \multicolumn{2}{|c|}{ On site measurement } & \multicolumn{2}{|c|}{ 3D model } \\
\hline & Trend & Plunge & Trend & Plunge & Trend & Plunge & Trend & Plunge \\
\hline$\sigma_{1}$ & 147 & 29 & 179 & 36 & 140 & 10 & 173 & 13 \\
\hline$\sigma_{2}$ & 244 & 11 & 255 & 85 & 261 & 71 & 317 & 71 \\
\hline$\sigma_{3}$ & 352 & 59 & 1 & 37 & 47 & 16 & 79 & 10 \\
\hline
\end{tabular}

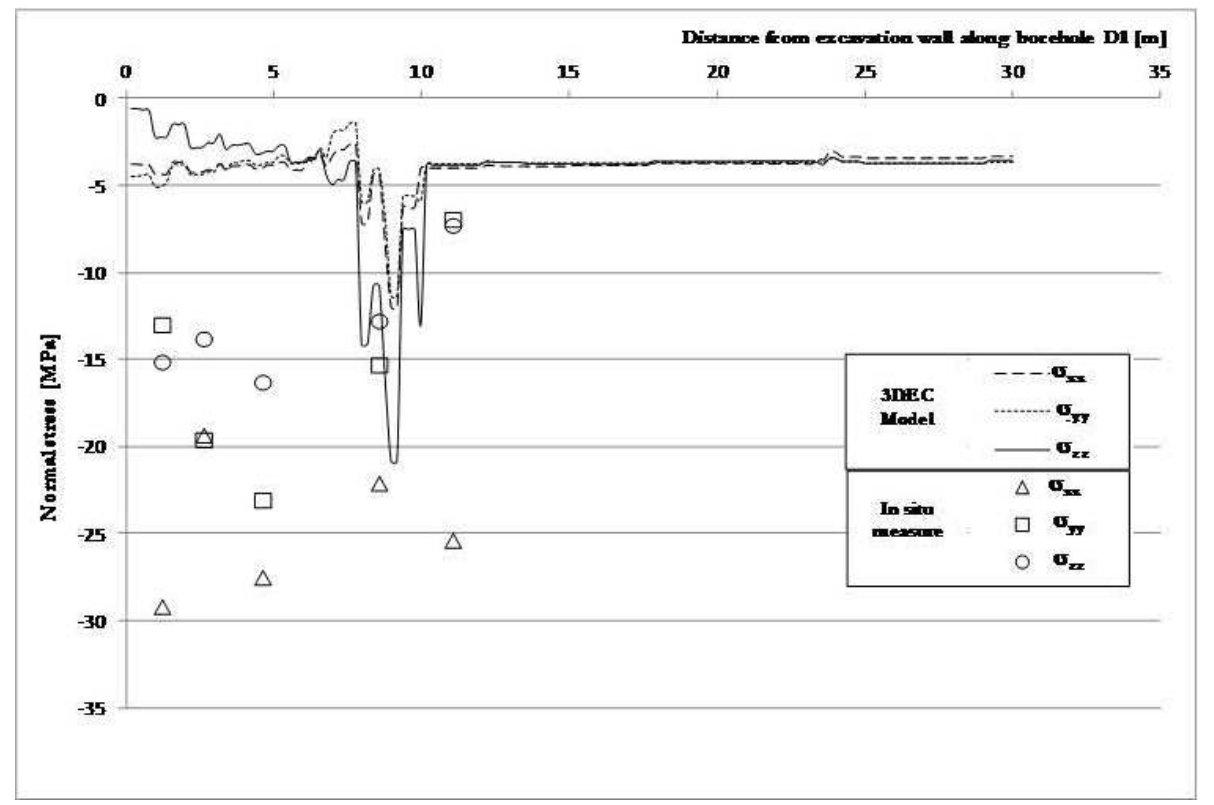

Fig. 14 Comparison of the in situ measured and M1 numerically modelled stresses.

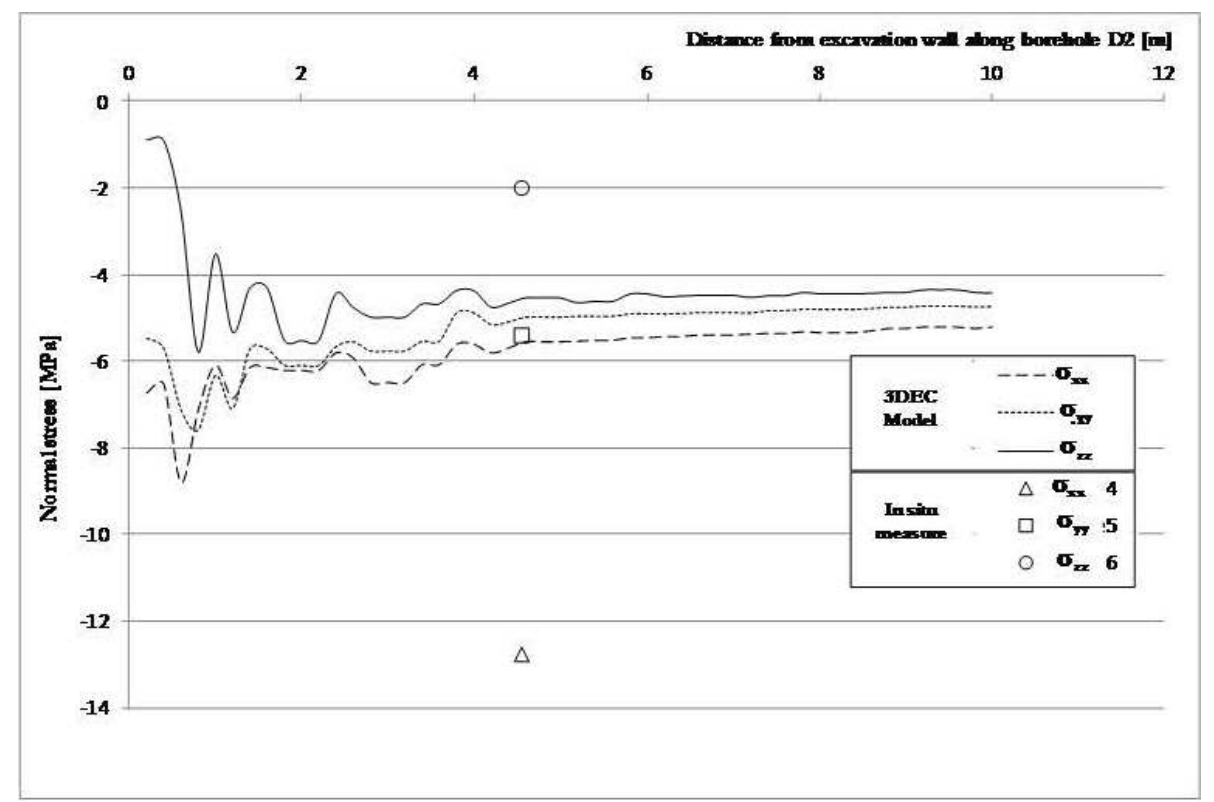

Fig. 15 Comparison of the in situ measured and M2 numerically modelled stresses. 
approximated reality, an evaluation process considered the fact that some simulations better approximated certain stress components, while others were better at interpreting the orientations of the principal stresses' action lines.

The global reliability of each model was then evaluated by calculating an "equivalent percentage error" that considered the percentage error when evaluating the intensity of each principal stress component $\left(\Delta \sigma_{\mathrm{i}}\right)$ and estimating the angular orientations of the principal stress directions $\left(\Delta \varphi_{i}\right)$. The error computation has been carried out in correspondence of each in situ measurement point. The difference between measured and computed value has been computed and the error for each model is the sum of the errors evaluated in each considered point.
As a result, the values and directions of the principal stresses were calculated for each of the analyses under study and the corresponding measurement positions, and the differences with respect to the corresponding in situ measurements were determined, in terms of both value:

$\Delta \sigma_{i}=\sigma_{i-m}-\sigma_{i-c}$

and orientation:

$\Delta \phi_{i}=\phi_{i-m}-\phi_{i-c}$

where $\varphi$ is the acute angle between the lines of action of the principal in situ stresses and the modelled stresses. The subscript $i$ is referred to each principal stress $(1,2$ and 3$), m$ to the in situ measurements and $c$ to computed values.

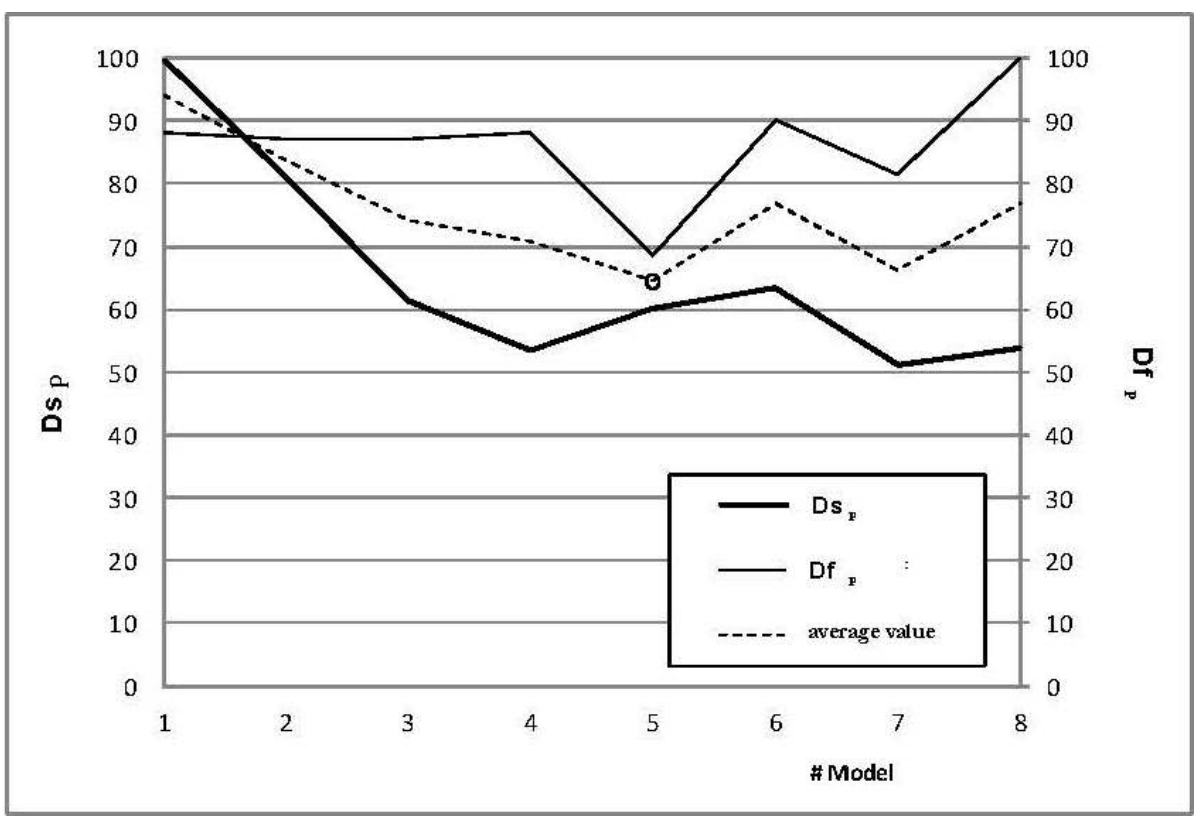

Fig. 16 Equivalent percentage errors calculated for each model under study.

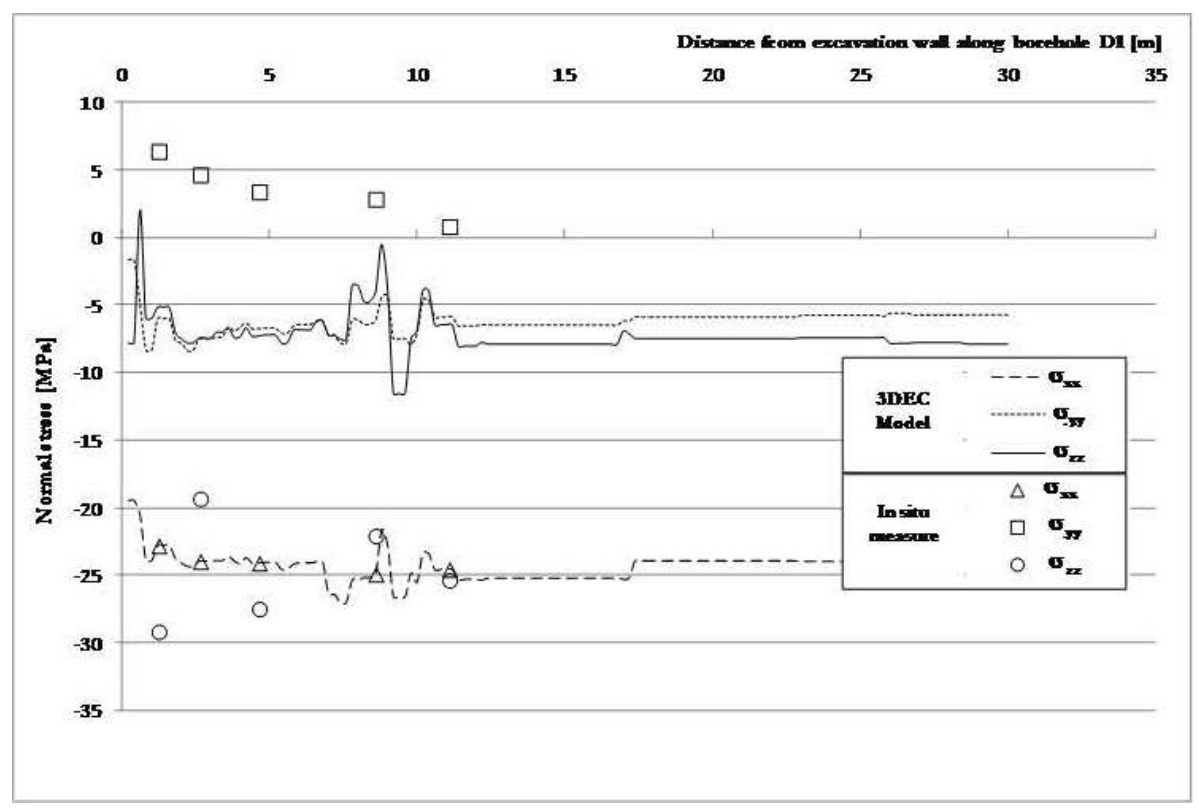

Fig. 17 Comparison between the measured and computed stresses in borehole 5. 
The equivalent error values were then calculated for each model by considering the three stress components simultaneously:

$$
\begin{aligned}
& \Delta \sigma=\Delta \sigma_{1}+\Delta \sigma_{2}+\Delta \sigma_{3} \\
& \Delta \phi=\Delta \phi_{1}+\Delta \phi_{2}+\Delta \phi_{3}
\end{aligned}
$$

The equivalent percentage error was determined by normalising the values with respect to the maximum value of $\Delta \sigma$ and $\Delta \varphi$, respectively:

$$
\begin{aligned}
& \Delta \sigma_{p}=\frac{\Delta \sigma}{\max \Delta \sigma} 100 \% \\
& \Delta \phi_{p}=\frac{\Delta \phi}{\max \Delta \phi} 100 \%
\end{aligned}
$$

In this way, it was possible to determine the percentage errors made by each model (Fig. 16) and sum the effects of these errors. The simulation of borehole 5 most accurately minimised the modelling error for a non-lithostatic condition, non-symmetrical confining stress state and realistic stress due to slope topography. A comparison between the measured and calculated stresses is shown in Figure 17.

\section{CONCLUSIONS}

The results of this study indicated that good correspondence between an in situ measured stress state and that calculated with numerical modelling could be obtained only by imposing boundary conditions that were difficult to hypothesise for the stress state in a previous calibration phase. Unlike in a previous study by the authors (Ferrero et al., 2013), in this case it has not been possible to satisfactorily obtain a reasonable estimate of the orientation and magnitudes of the stress field in the area of the excavation.

In fact, it was observed that the application of a gravitational load in the case under study led to the underestimation of the measured vertical stress state. It is also important to note that the vertical stress was the minimum principal stress in this case. The maximum principal stress appeared to be a horizontal compression force perpendicular to the discontinuity system, which was most likely due to the residual stresses derived from the Apuan Alps' orogeny process. The metamorphic Apuan complex was in fact the result of tectonic phases that occurred during Alpine orogeny, and it is also in line with the stress model proposed by Sheorey (1994), suggesting large horizontal stress near the surface.

The difference between the in situ measurements and numerical models could have resulted from the complicated factors that were involved in determining the stress state, factors such as the presence of tectonic forces that are still acting on the site today, which make the accurate calculation of stress due to simple gravitational loads unfeasible.

Another possible reason for our inability to derive a realistic stress model can be linked to the lack of information on relevant geological features around the excavation. Finally, in complex structural zones like the one here analysed, it can be very difficult to identify stress trends, unless a very detailed geomechanical knowledge of the area is available, which is very often not the case.

\section{ACKNOWLEDGMENT}

The authors would like to thank Dr. Ing. D. Gullì for supplying the data concerning the stress measurements and the geostructural and morphological evaluation of the site. The authors also wish to thank the Spanish Ministry of the Economy and Competitiveness for partial funding, awarded under Contract Reference No. BIA2014-53368-P, partially financed by ERDF funds from the EU.

\section{REFERENCES}

Alejano, L.R., García-Bastante, F., Alonso, E. and Taboada, J.: 1999, Back-analysis of a rockburst in a swallow gypsum room and pillar exploitation. In: Vouille, G. and Berest, P. (Eds): Proc. 9th Int. Congress on Rock Mech., 1, 1077-1080.

Alejano, L.R., Taboada, J., García-Bastante, F. and Rodríguez, P.: 2008, Multi-approach back-analysis of a roof collapse in a mining room excavated in stratified rock. Int. J. Rock Mech. \& Min. Sci., 45 (6), 899-913. DOI: 10.1016/j.ijrmms.2007.10.001

Amadei, B. and Stephansson, O.: 1997, Rock Stress and its Measurement. Chaman \& Hall, London and New York. DOI: 10.1007/978-94-011-5346-1

Burtan, Z., Zorychta, A., Cieślik, J. and Chlebowski, D.: 2014, Influence of mining operating conditions on fault behaviour. Arch. Min. Sci., 59 (3), 691-704. DOI: 10.2478/amsc-2014-0048

Diederichs, M.S.: 1999, Instability of Hard Rockmasses: The Role of Tensile Damage and Relaxation. PhD Thesis, University of Waterloo, Ontario, Canada.

Ferrero, A.M., Godio, A., Sambuelli, L. and Voyat, I.H.: 2007, Geophysical and geomechanical investigations applied to the rock mass characterisation for distinct element modelling. Rock Mech. Rock Eng., 40 (6), 603-622. DOI: 10.1007/s00603-006-0092-9

Ferrero, A.M., Migliazza, M. and Spagnoli, S.: 2009, Theoretical modelling of bowing in cracked marble slabs under cyclic thermal loading. Constr. Build. Mater., 23 (6), 2151-2159.

Ferrero, AM., Migliazza, M., Segalini, A. and Gulli, D.: 2013, In situ stress measurements interpretations in large underground marble quarry by $3 \mathrm{D}$ modelling. Int. J. Rock Mech. \& Min. Sci., 60, 103-113. DOI: $10.1016 / j . i j r m m s .2012 .12 .008$

Faihurst, C.: 2003, Stress estimation in rock: a brief history and review. Int. J. Rock Mech. \& Min. Sci., 40 (7-8), 957-973. DOI: 10.1016/j.ijrmms.2003.07.002

Figueiredo, B., Cornet, F.H., Lamas, L. and Muralha, J.: 2014, Determination of the stress field in a mountainous granite rock mass. Int. J. Rock Mech. \& Min. Sci., 72, 37-48. DOI: $10.1016 / \mathrm{j} . \mathrm{ijrmms} .2014-07-017$

Husdon, J.A. and Cornet, F.H.: 2003, Special issue on rock stress estimation (Preface). Int. J. Rock Mech. \& Min. Sci., 40 (7-8), 955.

DOI: $10.1016 /$ j.ijtmms.2003.08.001 
Husdon, J.A.: 2010, Underground radioactive waste disposal: The rock mechanics contribution. Proc. ISRM Int. Symp. 2010 \& 6th ARMS. New Delhi. Ed. Central Board for Irrigation and Energy.

Itasca: 2005, 3DEC: User's guide, Itasca Consulting Group Inc., Minneapolis.

Itasca: 2005, UDEC (Universal Distinct Element Code): User's guide, Itasca Consulting Group Inc., Minneapolis.

Konietzky, H. and te Kamp, L.: 2004, Numerical stress field modeling for underground structures. In: Konietzky, $\mathrm{H}$ (Ed.): Numerical Modeling of Discrete Materials in Geotechnical Engineering, Civil Engineering and Earth Sciences (Proc. 1st Int. UDEC/3DEC Symp.), 155-164.

Ljunggren, C., Chang, Y., Janson, T. and Christiansson, R.: 2003, An overview of rock stress measurement methods. Int. J. Rock Mech. \& Min Sci., 40(7-8), 975-989. DOI: 10.1016/j.ijrmms.2003.07.003

Matsuki, K., Nakama, S. and Sato, T.: 2009, Estimation of regional stress by FEM for a heterogeneous rock mass with large fault. Int. J. Rock Mech. \& Min. Sci., 46(1), 31-50. DOI: 10.1016/j.ijrmms.2008.03.005

Migliazza, M.R., Ferrero, A.M. and Spagnoli, A.: 2011, Experimental analysis of crack propagation in Carrara marble subjected to cyclic loads. Int. J. Rock Mech. \& Min. Sci., 48 (6), 1038-1044. DOI: $10.1016 /$ j.ijrmms.2011.06.016

Rocscience: 2010, DIPS: User's Guide, Rocscience Inc., Toronto.

Savchenko, S. and Gorbatsevich, F.: 2012, Estimation of the stressed state of the rock mass in the area of the Outokumpu deep drill hole (OKU), Finland. Acta Geodyn. Geomater., 9, No. 1(165), 31-42.

Segalini, A., Ferrero, A.M. and Giani, G.P.: 2009, Stability analysis of historic underground quarries. Comp. and Geotech., 37 (4), 476-486. DOI: $10.1016 /$ j.compgeo.2010.01.007

Sheorey, R.: 1994, A theory for in situ stresses in isotropic and transversely isotropic rocks. Int. J. Rock Mech. Min. Sci. Geomech. Abs., 31 (1), 23-34.

DOI: $10.1016 / 0148-9062(94) 92312-4$
Spagnoli, A., Ferrero A.M. and Migliazza, M.: 2011, A micromechanical model to describe thermal fatigue and bowing of marble. Int. J. Sol. Struc., 48 (18), 2557-2564. DOI: 10.1016/j.ijsolstr.2011.05.006

Sjöberg, J., Christiansson, R. and Hudson, J.A.: 2003, ISRM suggested methods for rock stress estimation-Part 2: Overcoring methods. Int. J. Rock Mech. Min. Sci., 40(7-8), 999-1010. DOI: $10.1016 /$ j.ijrmms.2003.07.012

Stephansson, O. and Zang, A.: 2012, ISRM suggested methods for rock stress estimation - Part 5: Establishing a model for the in situ stress at a given site. Rock Mech. Rock Eng., 45 (6), 955-969. DOI: $10.1007 / \mathrm{s} 00603-012-0270-\mathrm{x}$

$\mathrm{Su}, \mathrm{S}$. and Stephansson, O.: 1999, Effect of a fault on in situ stresses studied by the distinct element method. Int. J. Rock Mech. Min. Sci., 36 (8), 1051-1056. DOI: 10.1016/S1365-1609(99)00119-7

Waclawik, P., Ptáček, J. and Grygar, R.: 2013, Structural and stress analysis in mining practice in the Upper Silesian Coal Basin. Acta Geodyn. Geomater., 10, No. 2 (170), 255-265. DOI: 10.13168/AGG.2013.0026

Worotnicki, G.: 1993, CSIRO triaxial stress measurement cell. Comprehensive Rock Engineering, 3, 329-394. 


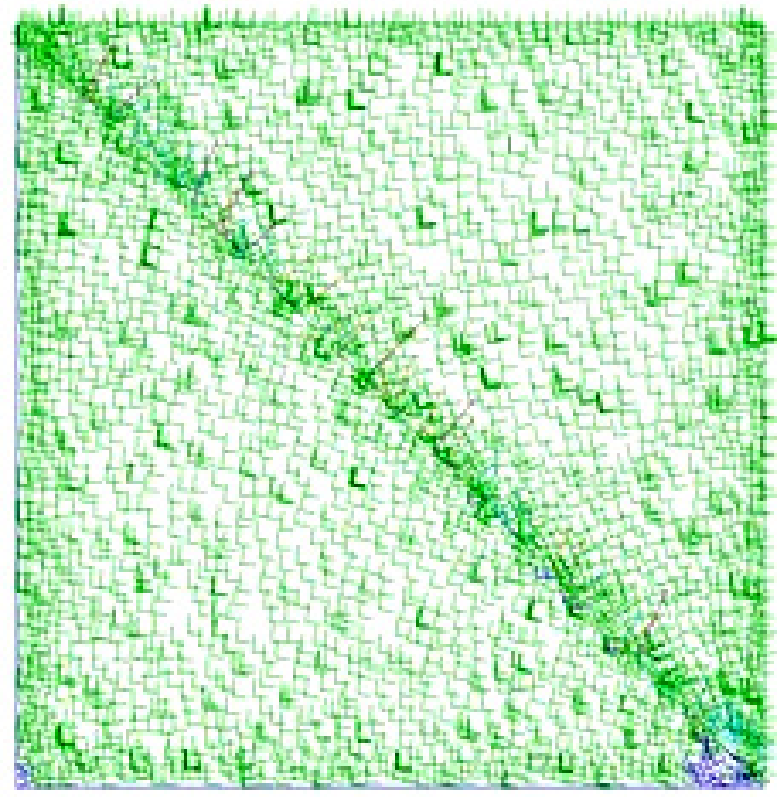

Fig. 2 Principal stresses in the central section parallel to the axis with a friction angle of $5^{\circ}$.

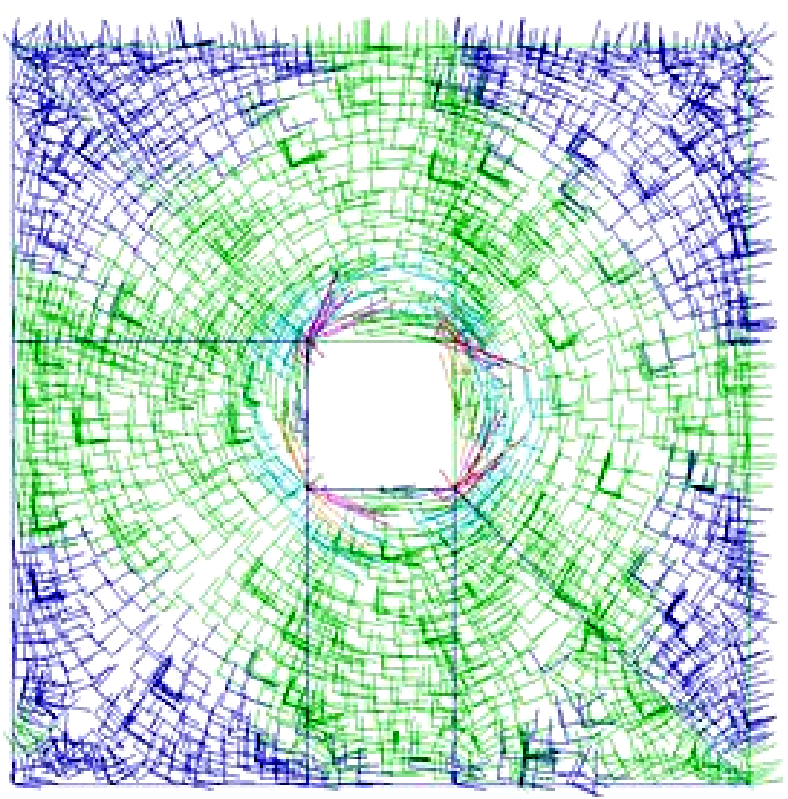

Fig. 7 Principal stresses in the central section parallel to the z-axis.

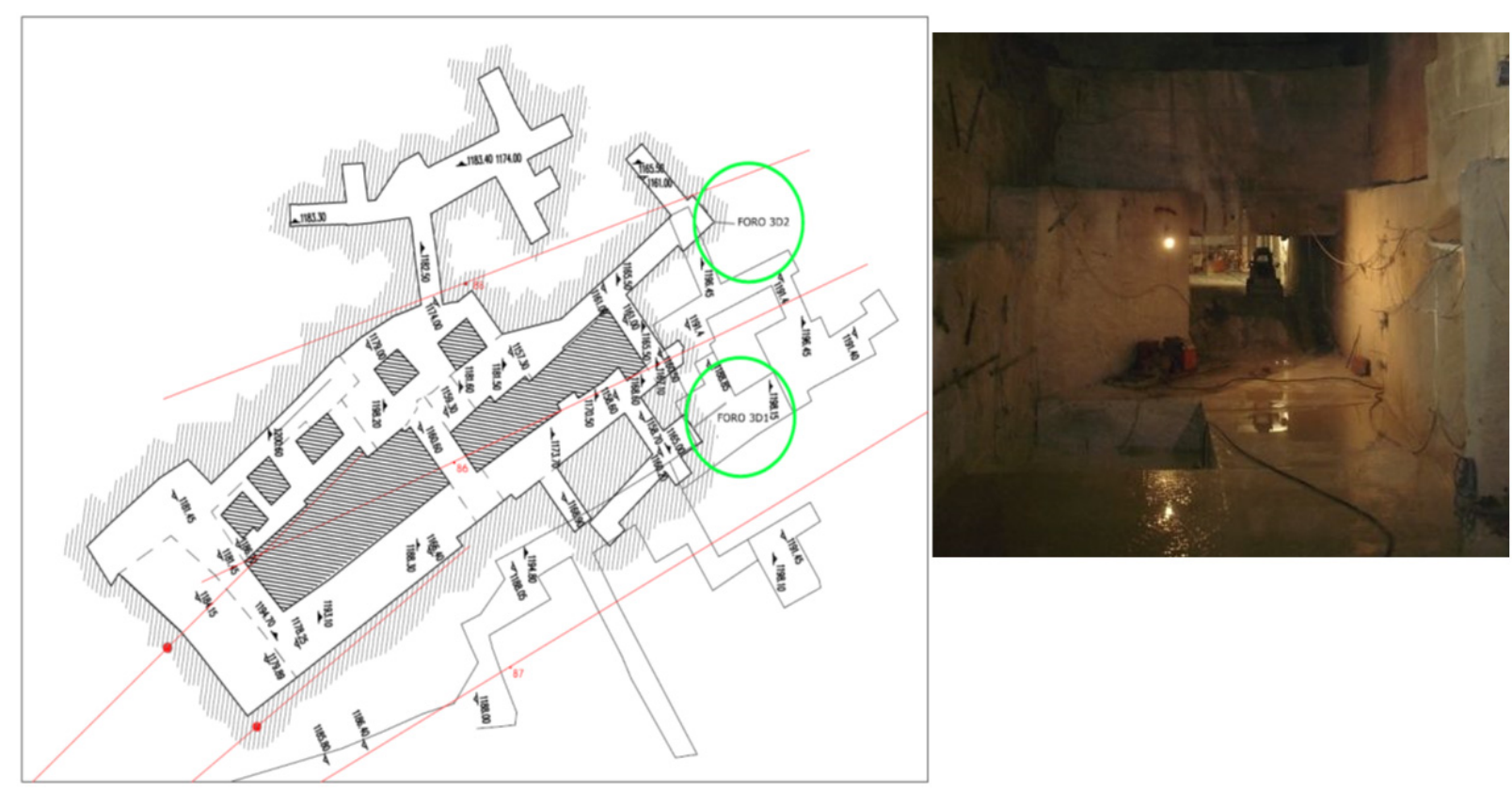

Fig.9 Quarry excavation maps indicating the in situ stress measurement sites. 


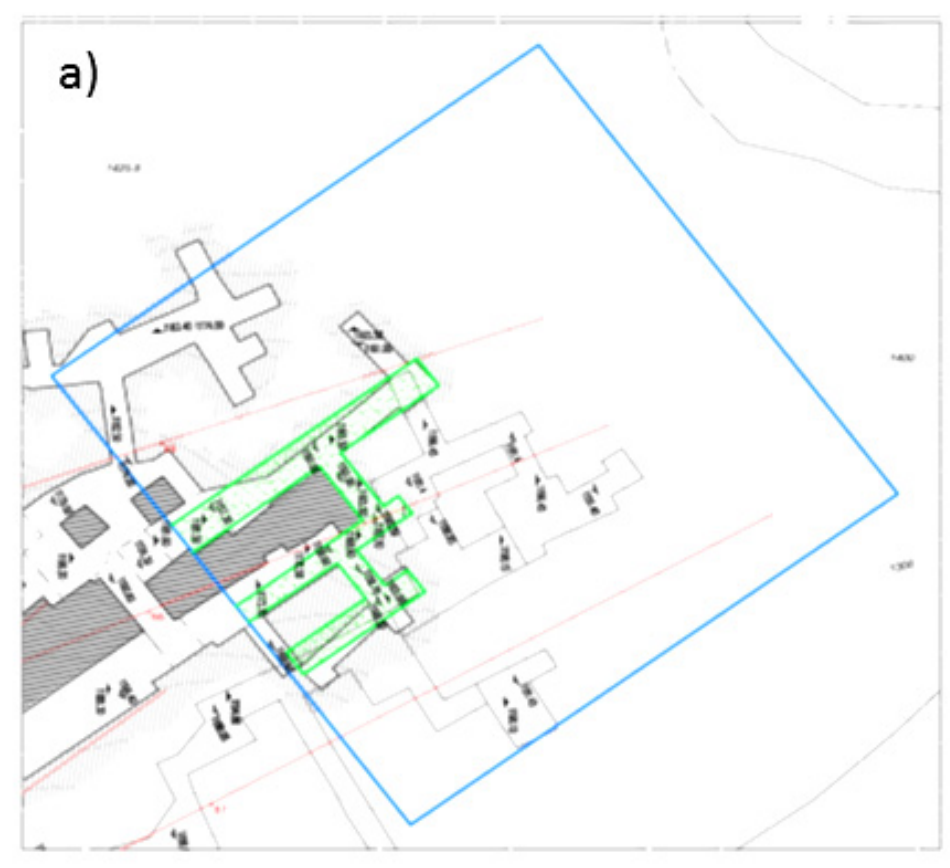

b)
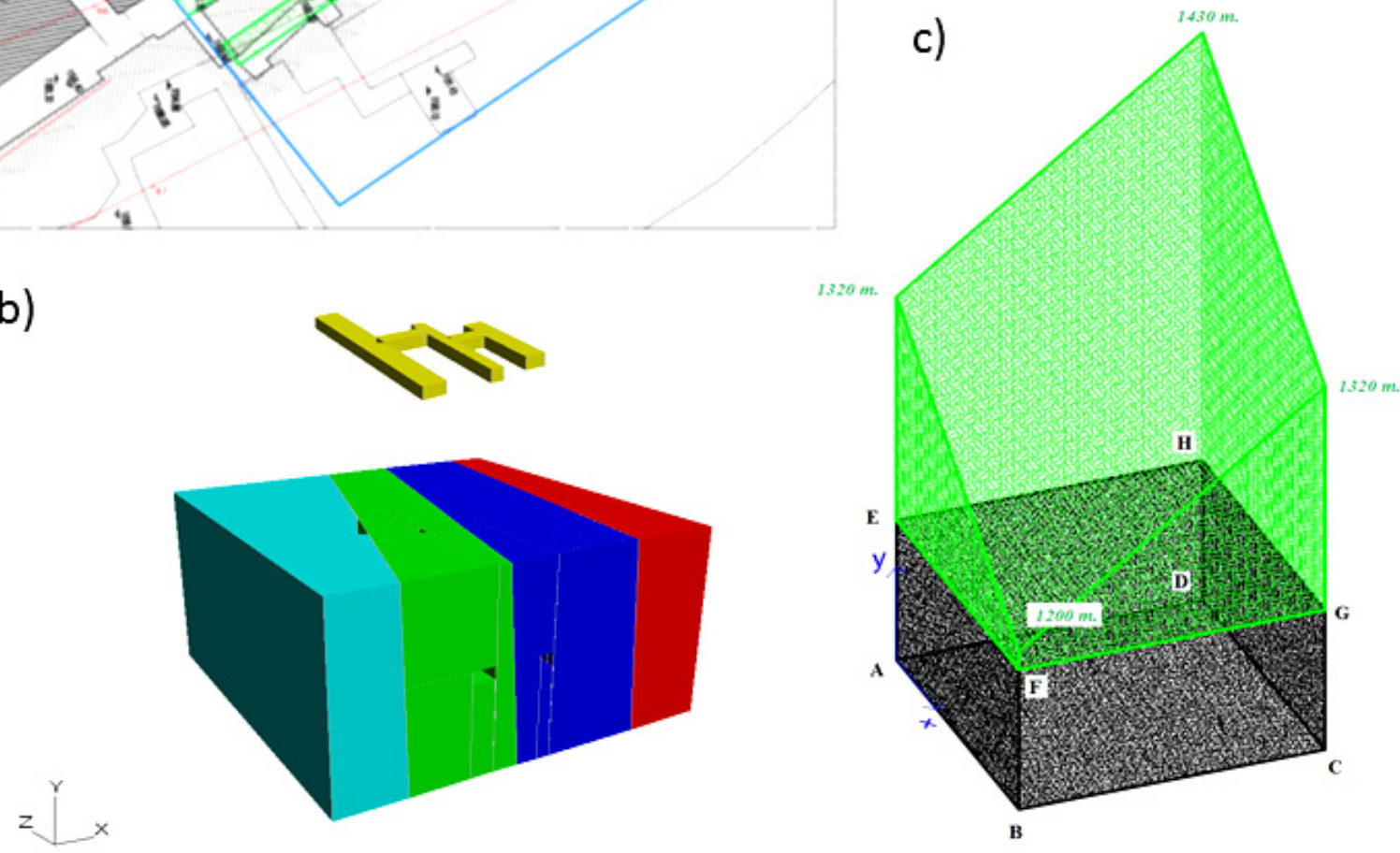

Fig. 12 Analysed portion of the excavation room and its simplification (a); geometric model (b) and load geometry (c).
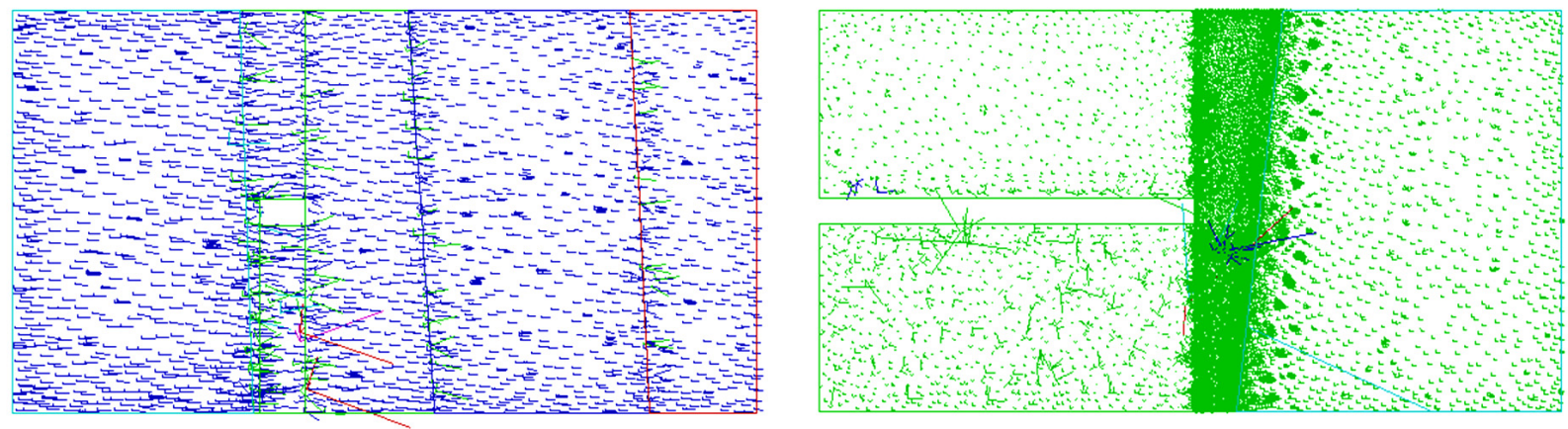

Fig. 13 Transversal and longitudinal sections of the model with respect to the excavation axis and representation of the principal stress components. 